\title{
The Effect of Divorce on Families' Life
}

\author{
Mulugeta Deribe Damota \\ Department of Psychology, College of Education and Behavioral Studies, \\ Madda Walabu University, Bale Robe, Ethiopia \\ PO box 247, Bale Robe, Oromia, Ethiopia
}

\begin{abstract}
Marriage and divorce are social issues as well as private concerns. Divorce is a major life stressor for the individuals involved, with potentially strong negative consequences for the mental and physical health of all members of the family. The basic purpose of this review is to provide detail information about the effect of divorce on families' life. Children dropout schools, engage in addiction, commit sex before marriage and develop delinquent behavior in the community they live in. Crimes, theft and immoral acts of conduct stem from divorced families. Divorce leads custodial parents to experience major changes in the their lives including a change in residential arrangements, economic disadvantage, loneliness associated with social network changes, and role strain associated with the task overload that results from having to care for children and work outside the home. In divorced couple's residential arrangements, economic status, social networks and role demands lead to deterioration in physical and mental health for the majority of individuals immediately following separation. Despite most societies of the world have negative attitude towards divorce, there are individuals who advocate marital dissolution for the reason that it results in various positive effects on their overall well-beings. the most causes for divorce are communication problem, lack of conflict management skills, falling out of love and lack of commitment to marriage financial problems, alcohol addiction, lack of maturity and physical abuse on the other hand, least causes are women education, having differences or rearing children, leaving home for a long time and lack of cooperation for household tasks were the least causes of divorce compared to others respectively. A lot has to be done before couples are going to divorce.
\end{abstract}

Keywords: Divorce, Marriage, life, parents, children

DOI: $10.7176 / \mathrm{JCSD} / 46-02$

Publication date:March $31^{\text {st }} 2019$

\section{Heading 1}

Introduction

\subsection{Background of the review}

Divorce is a common phenomenon in today's community. But still represent a major life stressor for the individuals involved, with potentially strong negative consequences for the mental and physical health of all members of the family. As a result the impact of divorce on child wellbeing has been the subject of research for several decades, and has long been viewed as the cause of a range of serious and enduring behavioral and emotional problems in children and adolescents (Kelly and Emery, 2003).Parents used to stay longer in marriage for the interest of their children's welfare even if they faced marital problems. But now so many couples end their marriage even for a simple reason and become single parents. No matter how single parent deals with this challenge, the consequences are far weightier as compared to children of parents living together (Gardner 2008). Divorce affects the couple who is ending their marriage, and affects their children as well. In US approximately one million children are affected by divorce each year (U.S. Census Bureau, 2002). Research has shown that parental divorce has many negative effects on children (Lewis \& Sammons, 2001). Academic failure, poor peer relationship and lack of commitment in relationship are some effects of divorce on children (Lewis \& Sammons, 2001). These problems do not diminish overtime and continue throughout adolescence and into adulthood (Kim, 2011).

Data from the US National Center for Health Statistics state that compared children from single parent and remarried families have more than twice chances to experience emotional and behavioral problem (Doolittle \& Deutsch, 1999).

When we come to Africa, according to Monama (2011), in 2007 about 52 percent of African urban parents are single. Data released by Statistics South Africa revealed a steady increase in the divorce rate from 1997 to 1999. However, this has begun to decrease, with the last reported rates being 582 divorces per 100000 married couples in 2001 (Locoh, 2001). In South Africa it's reality that one out of every two marriages ends in divorce (Collins, 2003). These are frightening statistics not only because it points to the breakdown of the family nucleus, but also because it means that 50 percent of young people come from broken homes. According to statistics of South Africa, (2005), 32484 divorces were recorded in 2005.

According to Tilson and Larsen (2000) in Ethiopia, $45 \%$ of all first marriages end in divorce or separation within 30 years, and $95 \%$ of the women marry by the age of 30 , and $45 \%$ of all first marriages ends in divorce 
within the first year, 34\% within 10 years, and $40 \%$ within 20 years(Tilson \& Larsen, 2000; p.360).In addition, the same study stated that two -third of the women divorce within the first five years of marriage (p.355)

The national research by Tilson and Larsen (2000) indicated 75\% of women who marry between age 11 and 13 divorces within 20 years. Rahel (1992) research works also states that, in $80 \%$ of her sample the divorced couple had children, in most case two or three.

This review paper is intended to provide brief information about the consequence of divorce on families' life.

\subsection{Rationale of Review}

Divorce has negative impact on the divorcees and their children socially, economically and psychologically. There is no organization aimed at provision of services for individuals and couples in the process of pre marriage, divorce and remarriage except few attempts by religious institutions.

Marriage and divorce are social issues as well as private concerns. The success and failure of our marriage have consequences beyond our personal lives. Individuals at the crossroads of divorce help not only just themselves and their families but also their neighborhoods, communities, and nation when they are able to repair their relationships and establish a healthy, stable marriage (Tizita, 2013). Divorce has become a serious problem; challenging the establishment of the family in a routine manner and causing severe impacts on the emotional and mental health of the individual especially, women.

In Ethiopia parents in general provide affections and care for their children as much as possible. However when divorce happen parents preoccupied by their own problem so that the adolescents feel alone and they faced a lot of problem which may affect their personality as well as their self-esteem. The rising rate of divorce in Ethiopia (Wondimu, 2007), means that many children are affected by the trauma of divorce.

\subsection{Objective of review}

\subsubsection{General objective}

The basic purpose of this of this review is to provide detail information about the effect of divorce on families' life.

\subsubsection{Specific objectives}

- To debrief the effects of divorce on parents life

- The effect of divorce on children's life

- Elucidate the causes for divorce

- Find out the positive sides of divorce

\subsection{Methodology}

These reviews were collected from different national and international published materials.

\section{Review on the effects of divorce on family life}

Here below the effect of divorce were clearly

\subsection{The effect of divorce on children}

According to Adamu and temesgen (2014), Children dropout schools, engage in addiction, commit sex before marriage and develop delinquent behavior in the community they live in. Crimes, theft and immoral acts of conduct stem from divorced families.

Shahram, Ali and Ghoobad (2012)cited in Adamu and temesgen (2014), identified the following points as possible consequences of divorce on children's psychological and social phenomena. These are:

a) Anti-social behavior and delinquency in children and adolescents,

b) Prostitution, especially in the poverty and ignorance

c) Abuse of women, men and children and using children in drug distribution and other illegal activities,

d) Aggression and maladjustment in children, and stray away from their home,

e) Academic failure, suicidal husband or wife or children,

f) Reduction in the desire to marry other people, especially children of divorced families, and

g) Children lose their confidence and do not imagine good future.

The consequences of divorce for children have been extensively studied in Western nations. Outcomes examined include, but are not limited to, academic achievement, health, behavioral problems, and emotional well-being. Researchers have generally found that divorce has a deleterious effect on children's outcomes (Amato 2000, 2001, 2010; Amato and Keith 1991b; Frisco, Muller and Frank 2007; Furstenberg and Kiernan 2001; Sun and Li 2002). Furthermore, the consequences of divorce are long-lasting, extending into adulthood. Adults whose parents are divorced have lower educational attainment, greater levels of depression, lower income levels, worse physical health, and a higher likelihood of ever being divorced (Amato and DeBoer 2001; Amato and Sobolewski 2001; Wolfinger et al. 2003). It is unclear to what extent the results of these studies are 
applicable for children living in Sub-Saharan Africa. It is quite possible that divorce can affect children similarly, regardless of their country of residence.

A distinction may be made between the short, medium and long term effects of divorce which are described below( Amato, 1993; Amato \& Kieth, 1991a; Amato \& Kieth, 1991b, Wallerstein, 1991).

Short term effects. For the 2 year period immediately following divorce, most children show some adjustment problems. Boys tend to display conduct problems and girls tend to experience emotional problems.

Medium term effects. The impact of divorce on children between the 3rd and 10th year following divorce may be statistically expressed in two ways: (1) as differences between the average or mean level of well-being or maladjustment of children of divorce compared with the mean level of well-being or maladjustment in intact families; (2) as the percentage of children of divorce who show adjustment difficulties. The mean level of maladjustment has consistently been found to be worse for children of divorce in comparison with those from intact families on a variety of measures of adjustment including conduct difficulties, emotional problems, academic performance, self-esteem and relationships with parents. This has led to the erroneous conclusion by some interpreters of the literature that divorce always has a negative effect on children.

Long term effects. In adult life a small proportion of individuals from families where divorce has occurred have difficulty making and maintaining stable marital relationships, have psychological adjustment difficulties and attain a lower socio-economic level in comparison with adults who have grown up in intact families.

\subsection{Divorce on Parents}

Divorce results different consequences on the economic wellbeing of men and women. A study by Bogale (2008) revealed that women experience an income decline of about $30 \%$ while male experienced about a $10 \%$ drop in income. Three years after the failure of their marriages, divorced women experience greater adversity than their married peers. During the first year after divorce, custodial mothers were more anxious, depressed, angry, and self-doubting than were married mothers. They also showed comparatively less affection to their children, communicated less with them, punished them more, and were more inconsistent in their use of discipline. In a similar way, Kotwal and Prabhakar (2009) found that divorced mothers experienced greater number of stressful events such as demotions, layoffs, accidents, critical illnesses and problems with their own parents than did married women.

Divorced mothers are also trapped in a vicious cycle of financial problems and other stressful life events. The results revealed that women tend to suffer from a feeling of rootlessness and lack of identity after divorce. This is especially true of women whose identity was formerly associated with that of their husbands. Studies reveal that most divorced women in Ethiopia are house wives and these divorced women gain custody of children without child support (Semhal, 2007). Serkalem (2006) also studied the causes and the socioeconomic impacts of divorce on women and their children and concluded that divorced women in Ethiopia are economically weak and usually engage in informal sectors like selling home made products (Tella, Arekie, Injera, etc), collecting wood and retailing activities after divorce. This makes their lives miserable. These single mothers are usually stressed. Serkalem ${ }^{e e}$ finding also revealed that the social relationship of divorced women does not enable them to get the moral and economical support they need.

Life changes Divorce leads custodial parents to experience major changes in the their lives including a change in residential arrangements, economic disadvantage, loneliness associated with social network changes, and role strain associated with the task overload that results from having to care for children and work outside the home.

Health Changes in divorced couples residential arrangements, economic status, social networks and role demands lead to deterioration in physical and mental health for the majority of individuals immediately following separation. However, for most people these health problems abate within two years of the divorce.

Mood Swings- Both men and women suffer extreme emotional liability in the period leading up to separation and for the two year post-separation period. An awareness of the opportunities for a new way of life and escape from the emotional pain of chronic marital discord both lead to periods of elation. The loss of a familiar way of life, the loss of a longstanding partner and a fear that alone one may not meet the extraordinary challenges that go with being a single person or a single parent commonly are associated with episodes of depressed mood.

Identity Problems- For women in particular, separation is associated with a crisis of identity. Prior to separation many women define themselves in terms of their husbands or their children. Also women may rely on their husbands to develop a social network of friends. After separation, women who have relied on their husbands for self-definition find that they experience confusion about their identity. They have to redefine their self-concept in terms of their own role and develop their own social network. Women who have jobs outside the home experience fewer identity problems in the aftermath of divorce.

\subsection{Positive sides of divorce}

As indicated by a range of researches, despite most societies of the world have negative attitude towards divorce, there are individuals who advocate marital dissolution for the reason that it results in various positive effects on 
their overall well-beings. Even if individuals pass through the most unhappy and turbulent situation, there are also moments that help them to see the positive sides of marital breakup. As research findings show, such individuals become more optimistic about their lives in the aftermath of divorce (Boon, 2005).

There are various factors that make the disintegration of marital union favorable for individuals who undergo through the divorce process which enable them maintain their well-being.

According to Boon (2005), although the negative aspects of divorce for women have been overemphasized, divorce also has beneficial effects particularly if their marriage was abusive and violent that provides a solution to escape from a dissatisfying and abusive marriage.

Likewise, it is shown that individuals after marital disintegration eventually feel relief from a violent relationship. This is because their marital breakup stops the tension and the emotional strain they used to experience in their offensive marriage. Hence, the ending of problematic relationships leads to an improvement in individualsee psychological and physiological wellbeing (Gomez, n.d).

In addition, studies have revealed that most women in the aftermath of marital disruption achieve enhanced personal growth that leads to an important psychological functioning. Some divorced women become fearless and spirited as they become released and are able to use the situation to start an important stage of emotional growth. Similarly, Writer (2010) pointed out that divorce allows women to interact with the society freely and to raise their children in their own ways without being dictated by their husbands. Furthermore, in consequence of the divorce, women are less occupied to their husbands ${ }^{e e}$ disposition and needs and they got the freedom to spend time alone in their own space. Studies also indicate that divorced women report greater self-rule in their lives than married persons (Boon, 2005).

Moreover, women following divorce are able to experience their sense of autonomy that make them free from unwanted relationships and allows them to heal from their grievances and to move on with their lives as a result of the ending of marital relationship. The other positive impact of divorce is that it helps divorcees to revitalize themselves. As indicated by different studies, following divorce individuals are able to entertain themselves without restriction, to be involved in whatever they like and to forming new social networks (Gomez, n.d).

\subsection{Causes of divorce}

In addition Ambert, (2009), put the following summary points as a cause for divorce. This are:

The first four years are the riskiest for marriages: Living together before marrying is associated with an enhanced risk of subsequent marriage breakdown. However, this enhanced risk is not due to premarital cohabitation but to the characteristics of those who cohabit.

Second and subsequent marriages following divorce have a slightly greater risk of breakdown than first marriages. Women are more likely than men to initiate divorce and to end the marriage. Women appear to have fewer doubts than men about their separation.

According to Adamu and Temesgen, the most causes for divorce are communication problem, lack of conflict management skills, falling out of love and lack of commitment to marriage financial problems, alcohol addiction, lack of maturity and physical abuse on the other hand, least causes are women education, having differences or rearing children, leaving home for a long time and lack of cooperation for household tasks were the least causes of divorce compared to others respectively

Schaefer, (2004) mentions the following as a few of the factors. First, liberal divorce laws, i.e. no-fault divorce laws, allowing a couple to end their marriage without fault on either side. Second, seeing divorce as a practical opinion for newly formed family not to have many children.

\section{Conclusions}

* Divorce results different negative consequences on families life.

- Divorce results physical problems among couples and their children

- Psycho-social and Mental problems among couples and their children

- Economic problems among couples and their children

- Divorce results Academic problems among children

* Divorcé has also positive side which is relief from chaotic relationship.

* Living together before marrying, Second and subsequent marriages, communication problem, lack of conflict management skills, falling out of love and lack of commitment to marriage financial problems, alcohol addiction, lack of maturity and physical abuse.

\section{Implications}

Based on the reviews collected from different researches, the reviewer for warded the following implication.

- As a different finding indicates the rate of divorce is increasing rapidly in the world in general and escalating in developing countries like Ethiopia. So, due consideration should have to be taken to 
decrease this number. From this in courts different mechanism should have to be taken to keep couples marriage like marriage counseling. Even if we don't have marriage counselors in our country those are working in court, individuals (lawyers) can use different mechanism to save couples marriage rather than simply following constitutions.

- Nowadays marriage is becoming very simple for most individuals than before mean they are simply following their current love which might not be true love. In psychology true love is the combination of passion, commitment and intimacy. Without these variables we cannot say they do have complete love. So working on the backgrounds of those coupes relationship plays indispensable role to save couples marriage.

- Religious institutions plays significant role in marriage. As marriage is a big institution, and have good contact with their religious fathers, the problems which were very difficult can be solved.

- Awareness creation is very important in saving couples marriage. Providing psycho education that is the teaching the society importance of marriage and the physical, social psychological, and economic disadvantages of divorce might help especially illiterate communities.

- Professionals from psychology, sociology, business and economics, health, law are very prone to provide information for our communities through different projects and other activities.

\section{References}

Adamu A., Temesgen M., (2014) Divorce in east Gojjam zone: rates, causes and consequences Wudpecker Journal of Sociology and Anthropology . Vol. 2(1), pp. 008

Amato, P.R.and D.D. DeBoer. 2001. "The transmission of marital instability across generations: Relationship skills or commitment to marriage?" Journal of Marriage and Family 63(4):1038-1051.

Amato, P.R.and B. Keith. 1991a. "Parental Divorce and Adult Well-Being - A Metaanalysis " Journal of Marriage and the Family 53(1):43-58.

- 1991b. "Parental Divorce and the Well-Being of Children - A Meta-Analysis " Psychological Bulletin 110(1):26-46.

—. 1991c. "Separation From a Parent During Childhood and Adulthood Socioeconomic Attainment " Social Forces 70(1):187-206.

Amato, P.R.and J.M. Sobolewski. 2001. "The effects of divorce and marital discord on adult children's psychological well-being." American Sociological Review 66(6):900-921.

Ambert, M.A. (2009). Divorce: Facts, Causes \& Consequences. (3rd Edition). York University

Bogale Abera (2008). Decrease the impact of divorce on the family: Ethiopian social policy reader. Volume. 3. Graduate school of social work: Addis Ababa University.

Boon, C. (2005).Women After Divorce: Exploring the Psychology of Resilience (Doctoral Dissertation). University of South Africa

Bray, J. \& Heatherington, M. (1993). Special Section: Families in Transition. Journal of Family Psychology, 7, $3-103$

Collins, J. (2003). Divorce and you. Young, October $\backslash$ November; 32-33.

Doolittle, D.B., \& Deutsch, R. (1999). Children and high-conflict divorce: Theory, Research and intervention. The Scientific Basis of Child Custody Decisions, 68, 425-440.

Frisco, M.L., C. Muller, and K. Frank. 2007. "Parents' union dissolution and adolescents' school performance: Comparing methodological approaches." Journal of Marriag and Family 69(3):721-741.

Furstenberg, F.F.and K.E. Kiernan. 2001. "Delayed parental divorce: How much do children benefit?" Journal of Marriage and Family 63(2):446-457.

Gardner. J.( 2008). Single parenting and effects on children-how single parenting can impinge on children . Reterived September 12, 2011 from the world wide.

Gomez, V. (n.d). Positive Effects in Life after Divorce.

Retrieved fromhttp://www.ehow.com/info_8385049_positive-effects-life-after-divorce.html

Heatherington, M. (1989). Coping with family transitions: Winners losers and survivors. Child Development, 60, $1-14$.

Kelly, J. B., \& Emery, R. E. (2003). Children"s adjustment following divorce: Risk and resiliency perspectives. Family Relations, 52, 352-362.

Kotwal Nidhi \& Prabhakar Bharti (2009). Problems Faced By Single Mother: post graduate Department of community resource management $\&$ extension. India

Lewis, J., Sammons, W.A.(2001). Helping children survive divorce. Contemporary pediatrics, 18(3), 103-114.

Locoh T, Thiriat M.(2001). Divorce et remarriage desfemmes en Afrique de I Quest.Lecasdu Togo, population, $50(1) ; 61-93$.

Monama T. (2011) 9 million kids with no dads. Retrieved 28 April, 2012 from the World Wide Web: http://www.sowetanlive.co.za/news/2011/04/05/9-million-kids-with-no- Dads 
Rahel Demeke (1992). „Divorce and its effects on societye. (Unpublished MA thesis ).Addis Abeba University. Raschke, H. (1987). Divorce. In M. Sussman \& S. Steinmetz (Eds). Handbook of Marriage and the Family (pp. 597-624). New York: Plenum.

Semhal Getachew(2007). Post divorce maintenance in Ethiopia: A viable option for divorced women-a draft document. Addis Ababa.

Serkalem Bekele(2006). Divorce: Its cause and impact on the lives of divorced women and their children. A comparative study between divorced and intact families. Addis Ababa University school of graduate studies. Master thesis.

Tilson, D. and Larsen, U (2000). Divorce in Ethiopia: The impact of early marriage and childlessness. Journal of Biosocial Science, Vol.32 No, 3, 355-372. USA: Cambridge University press.

Writer, A. (2010). Positive Effects of Divorce. Retrieved from http://women.writerarticles.org/

U.S. Bureau of the census (2002). Statistical abstract of the United States: 122th ed . Washington, D.C.U

Wallerstein , J. (1991). The long term effects of divorce on children: A review. Journal of the American Academy of Child and Adolescent Psychiatry, 30, 349-360. 